\title{
Developing Reflective Skills among First Year MBBS Students
}

\author{
Kadam, S.S. ${ }^{1}$, Kolhe, S.K. ${ }^{2}$, Sule, P.A. ${ }^{3}$ \& Kulkarni, V.V. ${ }^{4}$
}

\begin{abstract}
Introduction: Transitional period of students towards becoming professional should be aimed for making self-motivated learners by medical education. It is known that reflective writing expands the affective domain of persons and promotes mind mapping which are integral parts of good professional. The present study aimed to develop reflective writing skills of the medical students and to increase awareness about reflective writing skills.
\end{abstract}

Method: Prospective analytical study. Students were educated with a reflective writing skill workshop and requested to write four reflections after a specific interval with guidance. Reflections of students were analyzed for levels by the modified REFLECT Rubric method. Students were given individual feedback and /or by focus group discussion in between successive reflections. Feedback of whole process was taken from students.

Results: At the end of first reflection, $65 \%$ students had a clear concept of reflection whereas at the end of the fourth reflection, all students had a clear concept with achievement of a higher level of reflection; $33 \%$ students were transferred to the level of introspection; $11 \%$ students were found in reflection. However no student reached to the level of critical reflection.

Conclusion: Formal training and guiding for writing reflections over a period of time helped medical students to get sensitized and develop reflective writing skills. They had perception of enhanced skills of effective communication, ethical issues in medicine, empathy in medicine and patient's need. For holistic growth of students, teaching reflective writing skills to students should be incorporated.

Key words: Reflective skills, Medical students

\section{Introduction}

Reflection is a model for life-long learning (Epstein, 2008).

\footnotetext{
${ }^{1}$ Department of Physiology, Rajiv Gandhi Medical College and Chhatrapati Shivaji Maharaj Hospital, Thane, Maharashtra, India.

${ }^{2}$ Department of Anatomy, Rajiv Gandhi Medical College and Chhatrapati Shivaji Maharaj Hospital, Thane, Maharashtra, India.

${ }^{3}$ Department of Microbiology, Rajiv Gandhi Medical College and Chhatrapati Shivaji Maharaj Hospital, Thane, Maharashtra, India.

${ }^{4}$ Department of PSM, Rajiv Gandhi Medical College and Chhatrapati Shivaji Maharaj Hospital, Thane, Maharashtra, India.

Corresponding Author: Dr. Shilpa K. Kolhe

C-101, Classique, Neelkanth Palms, Ghodbandar road, Thane (West) - 400610, India.

Email: shilpakolhe2000@gmail.com
}

Reflection has been defined by Moon as a set of abilities and skills, to indicate the taking of a critical stance, an orientation to problem solving or state of mind (Hargreaves, 2016).

Motivating students in thinking of what they learnt in a given scenario and how they will apply that context in the future fosters critical thinking, the main rationale behind the reflective process. As a metacognitive process, reflection creates greater understanding of self and situations to inform future action (Hargreaves, 2016; Sandars, 2009). Understanding both theoretical and practical facets of the reflective process offers educational benefits too. The process of reflection occurs during and after the process of encounter, offering better understanding of the self and the encounter (Sandars, 2009; Jorwekar 2017). In the process

DOI: http://doi.org/10.4038/seajme.v14i1.235

(C) SEAJME. This is an Open Access article distributed under the terms of the Creative Commons Attribution
License (http://creativecommons.org/licenses/by/4.0/), which permits unrestricted use, distribution, and
reproduction in any medium, provided the original author and source are credited


of reflection, beliefs and assumptions may need to be revised as a result of the experience. Whenever this process becomes dramatic resulting in a major shift in perspective, in such circumstances, 'transformative learning' is said to have occurred (Mezirow, 1981). The main challenge of an educator is to stimulate and internalize this process.

One of the expected outcomes of undergraduate and postgraduate medical education is the ability to reflect (Sandars, 2009). There have also been attempts to include reflection in the curriculum of health care professional education for students to develop these skills (Mori et al., 2008). There are three main approaches to reflection in medical education, reflection for learning, reflection to develop a therapeutic relationship and reflection to develop professional practice (Sandars, 2009). This also helps the person understand what they already know (individual), identify what they need to know in order to advance understanding of the subject (contextual), make sense of new information and feedback in the context of their own experience (relational) and guide choices for further learning (developmental) (Wald et al., 2009; Wald et al., 2012). First year students while becoming competent professionals undergo a transition period of academic as well as personal development during the course (Novack et al., 1999). At the same time, they also face various encounters which affect their development. For this, an endeavor to introduce and develop reflective writing skills among first year MBBS students is proposed.

\section{Methods}

Type of study: Prospective analytical study

Place of Study: Department of Physiology and Anatomy, Rajiv Gandhi Medical College and CSMH, Thane.

\section{Sample size: 60}

Study period: 6 months after IEC (Institutional Ethics Committee) approval

IEC approval and written informed consent from participants was taken before commencing the study with maintenance of confidentiality throughout the study. The data was analyzed of four reflections which were completed at the scheduled time.

Following focus group discussion and brainstorming with 10 faculties, a reflective writing workshop module for students was developed, reviewed for content validation and prevalidated. As this project was part of FAIMER, it was reviewed by peers extensively by online discussion and modified accordingly. Implementation of the developed and prevalidated workshop module for first year students was done. Concepts of reflective writing of students were evaluated by pre and post validated questionnaire. Feedback about the workshop by a prevalidated questionnaire was taken.

Students were told to write reflections on two videos and two actual experiences with a few days gap. Reflections written by the students were analyzed for the levels of reflection by the modified REFLECT Rubric method. In the modified REFELCT Rubric method, reflections were analyzed in five levels - no concept, habitual, introspection, reflection and critical reflection. Unawareness of the concept by most students was identified during the pilot study. Sample size of the same was not included in present study. This was discussed with faculties and one more level of no concept was added in to same as per local need. The students who were not able to even describe the event and gave a general opinion about it were added in this level. After every reflection, it was evaluated for content and level of reflection, and then feedback was given to students either by focus group discussion for common and/ or individually for personal issues. Students were encouraged and offered practical advice closely for guided reflective writing after every reflection. A total of four reflections were given. Out of four reflections, two reflections were videos from movies on doctor-patient and doctor-doctor relationship whereas two were on actual events of their life. One was on process of terminal examination and other was on teaching learning methods. They were allowed to write reflections in any language. Feedback of the whole process was taken from students.

\section{Objectives}

At the end of study, all the students shall be sensitized about the concept of reflective writing skills and its importance and develop reflective writing skills.

\section{Results}

Quantitative data analysis was done with SPSS-20 and MS EXCEL and reflection analysis with the modified REFLECT Rubric 
method by two faculties separately, then compared and concluded for the level of reflection. This way of reflection assessment has reduced the threat of confounding factors while improvising the validity of assessment.

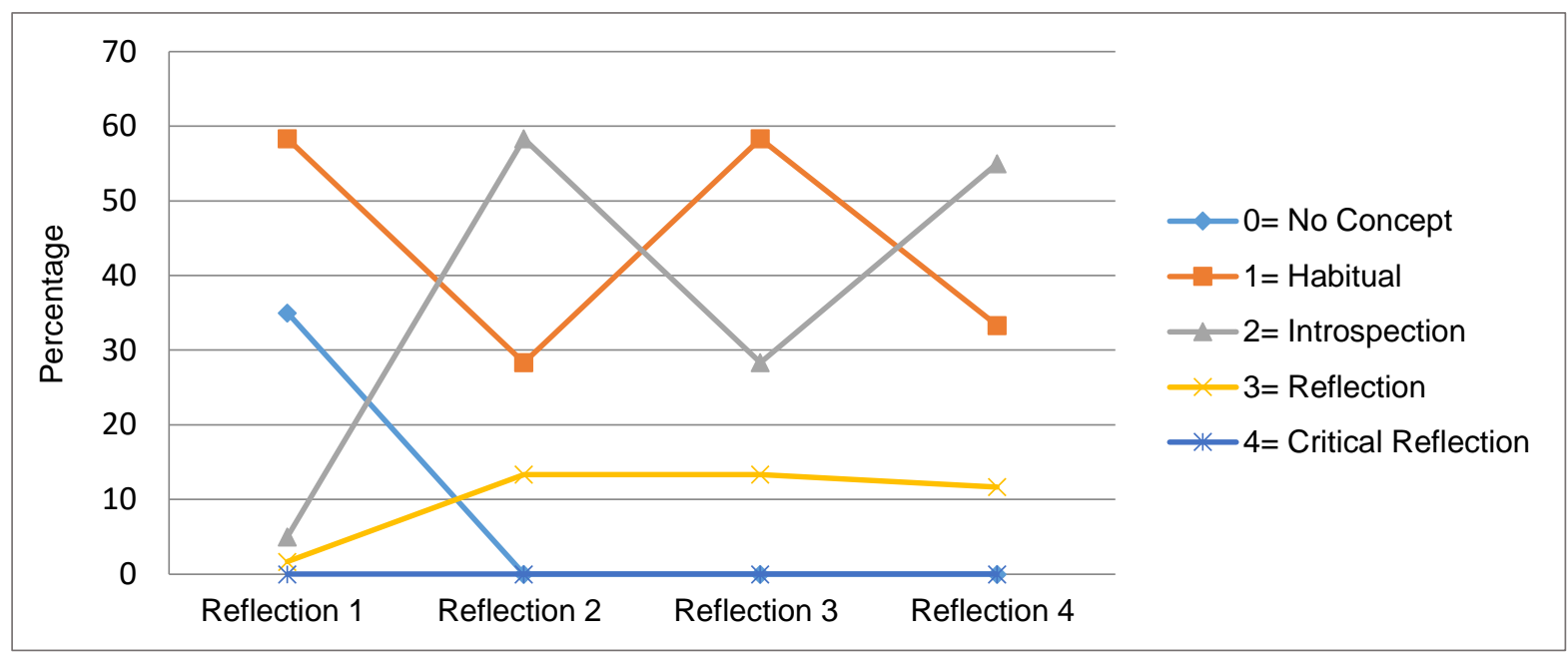

Figure 1: Variations in Reflection

$65 \%$ students had clear concepts at the end of the first reflection which was given at the end of the workshop, whereas at the end of 4th reflection $100 \%$ students had a clear concept. This shows that all students were sensitized and aware about the method of reflective writing skills. A drastic increase in count of student (from $5 \%$ to $55 \%$ ) to the level of introspection was seen at the end of 4th reflection. 33\% students were transferred to the level of introspection at the end of 4th reflection. However there was drop in the level of introspection during the third reflection and increase in the level of habitual reflection which became reversed at the end of the fourth reflection. This may be due to change in pattern of encounter; first two reflections were on the videos, whereas the third reflection was on an actual event which may have given apprehension and become difficult for applying the skills in a real time situation which they must have adjusted for during the fourth encounter. Few students were at the level of reflection at the end of second reflection. The percentage of it remained nearly the same throughout the study. None of the students could reach to the level of critical reflection at the end of the 4th reflection. After reaching the level of reflection, comparative fluctuations were less but there was also slowing of progress for the next level of reflective writing. The level of critical reflection is the highest level of reflection, achieving that requires many experiential encounters and is a slow process. Mechanisms which affect the transition of levels of reflection are complex.

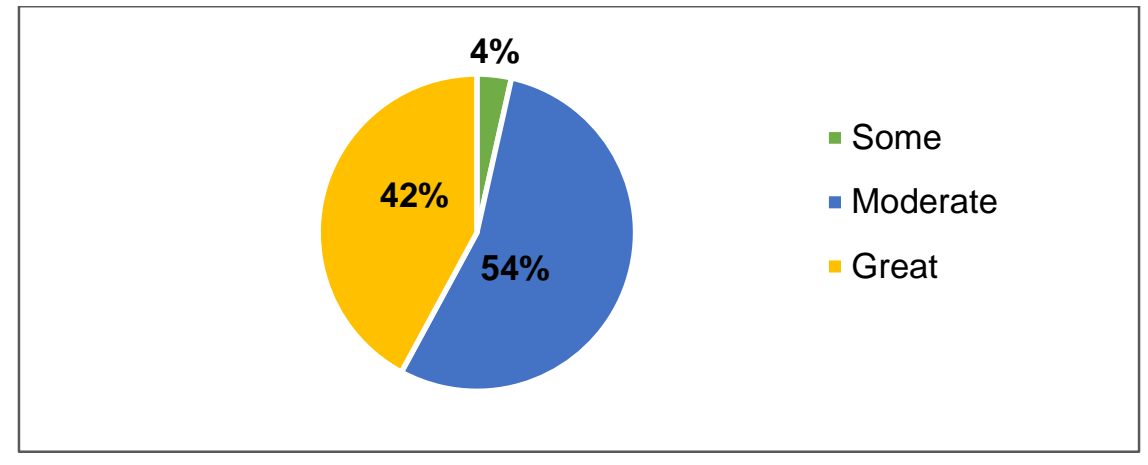

Figure 2: Enjoyment through Workshop 


\section{Student Feedback Results}

All except 03 students shared feedback, hence proportion was found on the basis of opinions of the remaining 57 students.
Almost $96 \%$ students enjoyed it a lot, whereas $4 \%$ mentioned about slight enjoyment. Out of that, $42 \%$ had opinioned great enjoyment with $54 \%$ students at moderate level of enjoyment when writing reflections.

Table 1: Enhancement

\begin{tabular}{lccccc}
\hline & $\begin{array}{c}\text { Reflective } \\
\text { Practice }\end{array}$ & $\begin{array}{c}\text { Effective } \\
\text { Communication }\end{array}$ & $\begin{array}{c}\text { Ethical } \\
\text { Issues in } \\
\text { Medicine }\end{array}$ & $\begin{array}{c}\text { Empathy in } \\
\text { Medicine }\end{array}$ & $\begin{array}{c}\text { Patient's } \\
\text { Need }\end{array}$ \\
\hline Not at all & $0(0)$ & $1(2)$ & $1(2)$ & $2(4)$ & $3(5)$ \\
Slight & $2(3)$ & $3(5)$ & $4(7)$ & $2(4)$ & $4(7)$ \\
Some & $8(14)$ & $16(28)$ & $17(30)$ & $12(21)$ & $11(19)$ \\
Moderate & $33(58)$ & $23(40)$ & $22(38)$ & $27(47)$ & $25(44)$ \\
Great & $14(25)$ & $14(25)$ & $13(23)$ & $14(24)$ & $14(25)$ \\
\hline
\end{tabular}

(Numbers in the parenthesis shows the percentage value)

Self-evaluation by students for personal enhancements such as Reflective practice skills, effective communication, ethical issues in medicine, empathy in medicine and patient's need during the process of reflective writing over a period was analyzed. Reflective practice skills, effective communication, ethical issues in medicine, empathy in medicine and patient's need were sensed as moderately improved skills in $58 \%, 40 \%, 38 \%, 47 \%$ \& $44 \%$ respectively whereas greatly improved skills in $25 \%, 25 \%, 23 \%, 24 \% \& 25 \%$ respectively by the students.

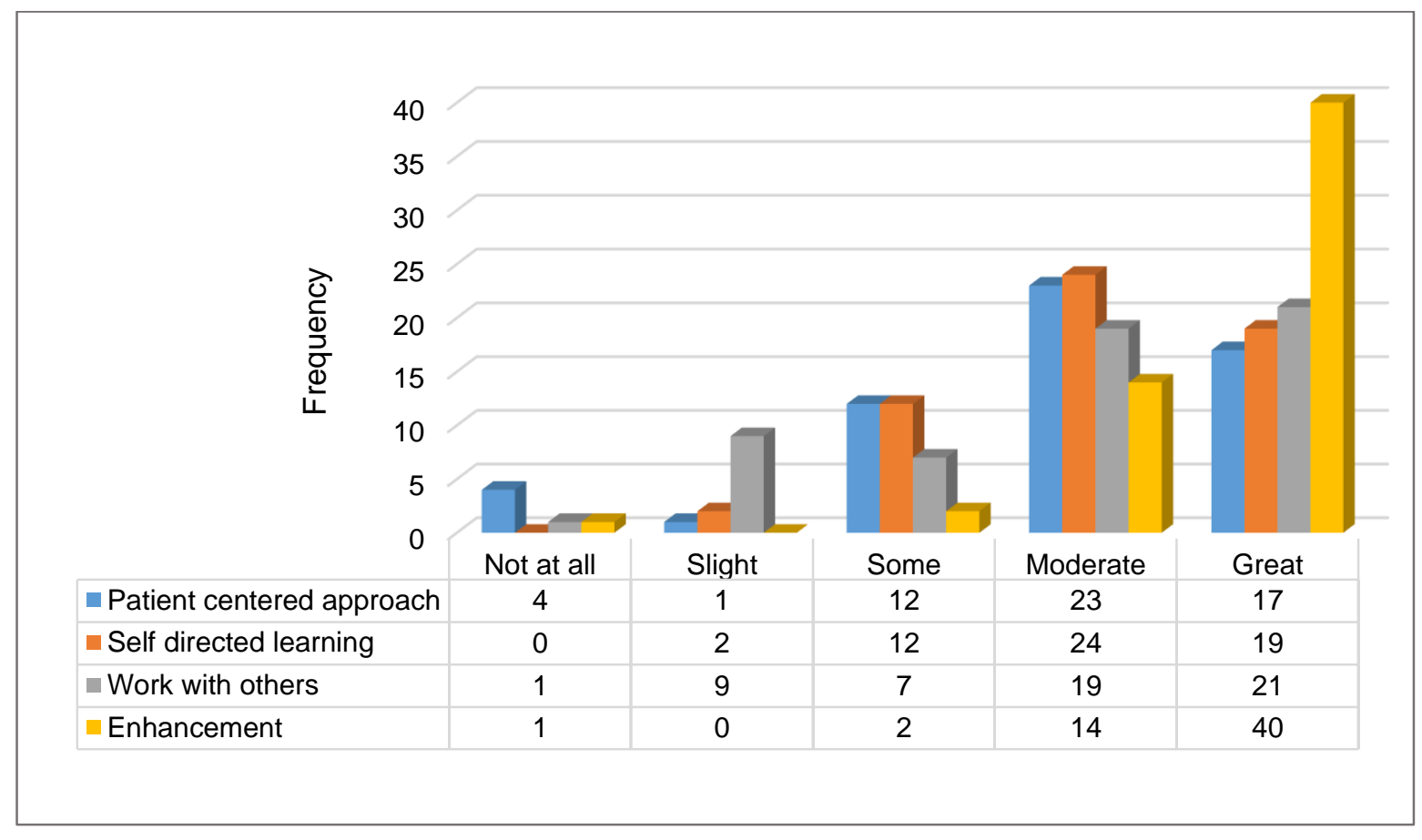

Figure 3: Uses of Workshop 
All students have graded this as a useful activity for self-directed learning. Out of them $42 \%$ of students have agreed that this was of great use. $70 \%$ students felt that they got great help to improve their knowledge of their own feelings and emotions. $40 \%$ students have opinioned that this activity helped them moderately to adopt a patient centered approach. 37\% students understood the use of reflective writing as important factor for working with others as a team.

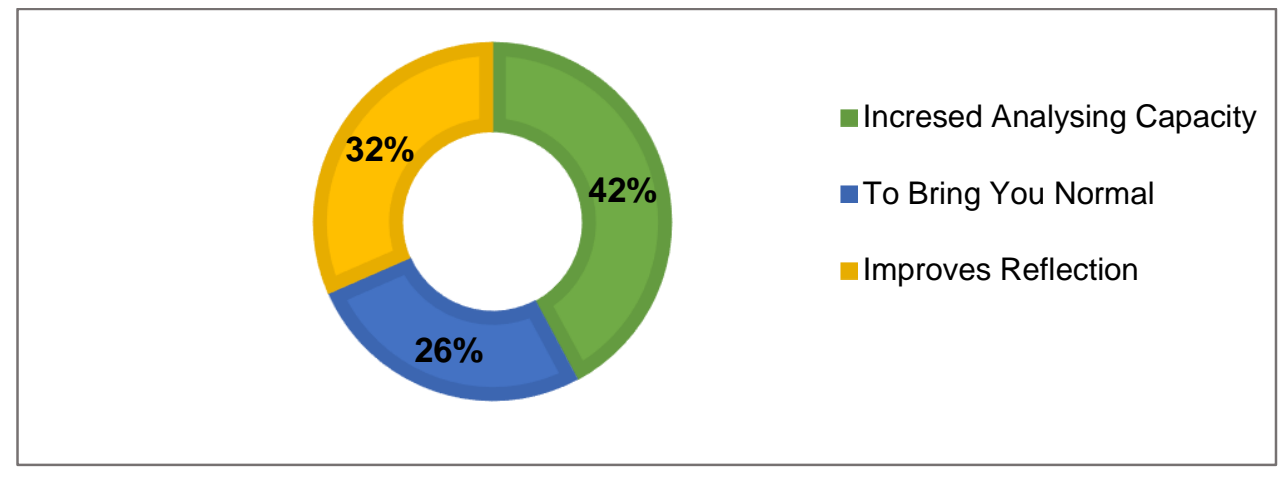

Figure 4: Advantages of the Workshop

By attending this workshop, $42 \%$ students opinioned that it will helped to increase their analyzing capacity, $32 \%$ said that such activity will improve their process of reflection whereas $26 \%$ students said that this will help them to cope up with stressful emotions to bring their thoughts back to normalcy.
While discussing with students about the easy and hard parts of the conducted workshop, $59.65 \%$ Students found analyzing the solution and writing the reflection easy. However, $57.89 \%$ students reported some tasks hard such as to chalk out action plan or to describe exact emotions in the write-up.

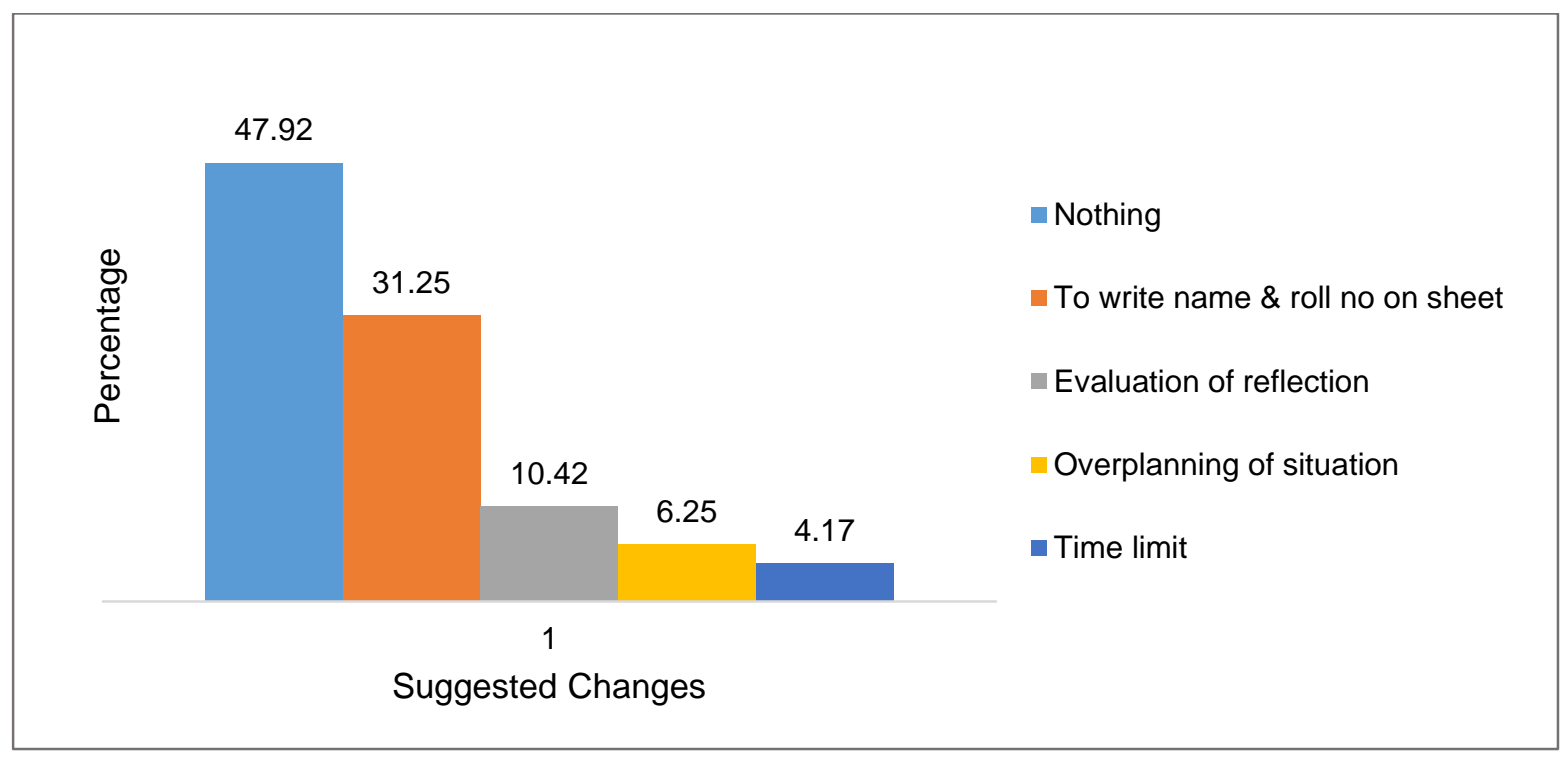

Figure 5: Suggested Changes for the Workshop 
While taking opinion from participants regarding requirement of any changes to the performed activity, 9 students did not give opinion. From remaining opinions of 48 students, $47.92 \%$ did not want any change in the workshop module; however $31.25 \%$ of students did not like to reveal their identity by writing their name and roll no on the worksheet. Additionally $4 \%$ students were pointed out the constraint of time and $6.25 \%$ were commented on over planning of the situation. $10.42 \%$ students felt evaluation was difficult to understand but they did not mention regarding its elimination or increase for content in the module.

\section{Discussion}

It is vital to develop skills and attitudes for lifelong learning in our students for them to grow not only professionally but holistically (Wald et al., 2012). This necessary quality includes self-directed learning which is enhanced by reflective practices (Mori et al., 2008). Reflective writing among medical students need not be intuitive. They can undergo development of this skill early which is responsibility of medical educators. The Aronson reports the benefits of written reflection as an instructional method as it guides students' critical thinking of their own learning process (Aronson, 2010).

This study revealed that it is possible to provide students an opportunity to practice the process of reflection and gradually improve in levels of reflective skills. This is reinforced by student's end analysis of first reflection showing that they did not have a clear concept of reflection but by the end of the 4th reflection none of the students were there without clear concept (Figure 1). This shows that all students were sensitized and aware about the whole process and method of reflective writing skills. It can also be speculated that more of such training may instill high quality reflecting skills in medical students enhancing their competence with an ethical and holistic approach. It is well documented that reflective summaries do support reflective practice (Wald et al., 2009; Wald et al., 2012). The present study was done in first year medical students which shows repeated guided reflective writing has improved their reflective skills. The new competency based curriculum implemented in India has incorporated reflection as part of the curriculum as early as in phase 1 . The reflections which phase 1 medical students are writing need to be analyzed and feedback should be given for the same with guidance to improve their reflective skills.

The level to which a student goes into deeper reflection depends on their reflecting ability (Sandars, 2009). None of the students reached to level of critical reflection at the end of 4th reflection session suggests students' generic reflective skills. It is a metacognitive slower process as many factors are part of it. Hence achieving a small change in such a short period of the study should be considered as a major change. Though a control group was lacking to validate the study, drastic increase in the count of students (from $5 \%$ to $55 \%$ ) to the level of introspection at the end of the 4th reflection demonstrated evidence that after repeated exposure there was improvement in the outcome.

Enjoyment always gives you better and long term learning. The reflective writing workshop and process was enjoyed by maximum students (Figure 2). Their self-evaluation for enhancement of effective communication, understanding patient's need, solving ethical issues and empathy in medicine which is basis of a good doctor patient relationship will help them achieve it (Table1). All students who participated in the study had commented on improved self-directed learning is one of the goals of the Indian Medical Graduate in the new competency based curriculum. Making a student more efficient self-directed learner will attain a lifelong learner in the medical professional.

In the present study, students have felt that it has expanded their analyzing capacity along with understanding of their own feelings and emotions (Figure 3). Understanding self is the first step of managing others which is required not only in the professional career but also in the personal life. Professional and personal lives though appearing separate but they are interdependent. Imbalance in any of it leads to impaired quality of life, ultimately affecting person as well as the community. Developing medical students for personal and professional growth by a holistic approach is possible with consistent reflective writing. Hence, it is important that medical students develop a routine to write reflections as early as possible so that the difficulty of deciding an action plan and writing reflections observed in present study can be overcome.

$31 \%$ students commented on anonymity while writing reflections or analysis (Figure 4). They had apprehension of sharing their opinions with 
teachers which may have affected their reflections in a few cases. The analysis is time and resource consuming (Figure 5) (Thomas, 2019). This can be taken as a limitation of the study along with no comparator group.

In present study it has been observed that incorporation of early reflective writing skills especially if guided, will be very effective even in a short duration (Vasudha et al., 2017). If it is done consistently it will surely change and will have high impact on the attitudinal aspects which is scope for future expansion of the study.

\section{Conclusion}

This study shows that all students got sensitized and aware about reflective writing skills. Most of the students have even improved in their levels of reflection. Hence, it can be concluded that teaching guided reflective writing skills to students should become an integral part of medical education to develop a holistic approach among students.

\section{Acknowledgement}

We are thankful to FAIMER faculties GSMC nodal center Mumbai, all the participant medical students and those helped us to complete this study from the Rajiv Gandhi Medical College, Thane.

\section{Conflict of Interest}

The authors declare no conflict of interest.

\section{References}

Epstein, R.M. (2008) Reflection, Perception and the Acquisition of Wisdom. Medical Education, 42, 11, pp.1048-1050.

Hargreaves, K. (2016) Reflection in Medical Education. Journal of University Teaching and Learning Practice, 13, 2, Available at: http://ro.uow.edu.au/jutlp/vol13/iss2/6
Jorwekar, G.J. (2017) Reflective Practice as a Method of Learning in Medical Education: History and Review of Literature. International Journal of Research in Medical Sciences, 5, 4, pp.11881192.

Mezirow, J. (1981) A Critical Theory of Adult Learning and Education. Adult Education, 32, 1, pp.3-24.

Mori, B., Batty, H.P. \& Brooks, D. (2008) The Feasibility of an Electronic Reflective Practice Exercise among Physiotherapy Students. Medical Teacher, 30, 8, pp.232-238.

Novack, D.H., Epstein, R.M. \&Paulsen, R.H. (1999) Toward Creating Physician-healers: Fostering Medical Students' Self-awareness, Personal Growth, and Well-being. Academic Medicine, 74, 5, pp.516-520.

Sandars, J. (2009) The Use of Reflection in Medical Education: AMEE Guide No. 44. Medical Teacher, 31, 8, pp.685-695.

Thomas, D.U. (2019) Automated Analysis of Reflection in writing: Machine Learning Approaches. International Journal of Artificial Intelligence in Education, 29, 2, pp.217- 257.

Vasudha, D., Reem, R.A. \& Ullas, K. (2017) Teaching and Assessing Reflecting Skills among Undergraduate Medical Students Experiencing Research. Journal of Clinical and Diagnostic Research, 11, 1, pp. JC01-JC05

Wald, H.S., Borkan, J.M., Taylor, J.S., Anthony, D. \& Reis, S.P. (2012) Fostering and Evaluating Reflective Capacity in Medical Education: Developing the REFLECT Rubric for Assessing Reflective Writing. Academic Medicine, 87, 1, pp.41-50.

Wald, H.S., Davis, S.W., Reis, S.P., Monroe, A.D. \& Borkan, J.M. (2009) Reflecting on Reflections: Enhancement of Medical Education Curriculum with Structured Field Notes and Guided Feedback. Academic Medicine, 84, 7, pp.830837. 